\title{
14
}

\section{The Right to Science}

\section{A Practical Tool for Advancing Global Health Equity and Promoting the Human Rights of People with Tuberculosis}

\author{
Mike Frick and Gisa Dang
}

\begin{abstract}
"We need research, not hysteria!" - Banner at New York City Gay Pride, June $1983^{1}$
"We need good science like we need clean water." - Glenda Gray, president, South African Medical Research Council, $2016^{2}$
\end{abstract}

Human rights play a tremendous role in successfully tackling communicable diseases worldwide. The application of the right to health with the rights to nondiscrimination and participation has created pathways for civil society involvement in the design, implementation, and oversight of health programs, and has created space to grow social movements in the global health sphere. Activists in the HIV/AIDS movement, such as the ACT-UP members quoted in the above epigraph, realized early in the course of the HIV epidemic that science, health, and human rights are inextricably linked; and that, in fact, the combination of scientific progress and respect for human rights will be essential for achieving an AIDS-free generation. Scientists working on infectious diseases have themselves voiced the intrinsic human rights dimensions of science, exemplified by South African Medical Research Council president Glenda Gray's comparison of good science to clean water; both are public goods and basic requirements of a life with dignity.

Given the deep connections between science and rights, one might assume that the right to science has provided a rallying point for social movements tackling health and human rights issues. The right to science - established by Article 27 of the Universal Declaration of Human Rights (UDHR) and Article 15 of the International Covenant on Economic, Social, and Cultural Rights (ICESCR) - speaks to many of the freedoms and entitlements at the heart of

1 As depicted in a photograph taken by Barbara Alper for Getty Images.

2 Glenda Gray. State of the Field and Future Direction of Research and Development for TB and HIV/ AIDS Vaccines. Presentation at: Vaccines are Needed to Conclusively End HIV/AIDS and TB. 21st International AIDS Conference. Durban, South Africa. July 18, 2016. http://programme.aids2o16.org /Programme/Session/1069. 
global health movements. ${ }^{4}$ Yet, the size and success of the HIV/AIDS movement remains exceptional; similar movements have not coalesced around other infectious diseases to the same extent. (The COVID-19 pandemic may yet spark social mobilizations rivaling the size and durability of those against HIV/AIDS, a potential explored in an addendum ending this chapter.) Nor has the right to science been analyzed in any form that comes close to matching analyses of the right to health advanced by civil society, scholars, and the United Nation (UN) system.

Consistent with the interrelation of human rights, the right to science cannot be entirely separated from the right to health and other rights, but is in fact a complementary right. Yet, global health advocates have so far not claimed the right to science as a practical tool for securing health and human rights. In this chapter, we show the importance of undertaking a detailed, applied analysis of the right to science for the elimination of tuberculosis (TB) as the world's deadliest infectious disease. We analyze the access and participation dimensions of the right to science, departing from a traditional right to health analysis to supply a workable entry point for advocacy for the global TB response. The discussion of two ethical pillars of participation - inclusion and reciprocity - illustrates how promoting the meaningful involvement of marginalized communities in TB research is a prerequisite for states' abilities to fulfil their obligation to ensure all people can enjoy the benefits and applications of scientific progress. The final section presents examples illustrating how activists have begun to invoke the right to science as a basic human right. These cases demonstrate the importance of disentangling the right to science from the right to health, even while acknowledging their interrelation, in order for this right to become a truly powerful avenue for advancing global health equity.

\subsection{TB RESEARCH: IN SEARCH OF STATE ATTENTION}

TB has killed more people than any other infectious disease in human history and remains the leading cause of death from a single infectious agent globally. ${ }^{6}$ In 2018 , 10 million people developed TB and 1.3 million died from the disease. The deadly persistence of TB stems, in part, from the failure of scientific advances to keep pace with an epidemic that has evolved both in response to and away from last century's medical interventions. Over time, TB has grown more difficult to treat and formed syndemics (i.e., epidemics that occur together and magnify each other's effects) with other global health threats such as HIV and diabetes. A review of TB research investments by the World Health Organization (WHO) concluded: "The present and future threat TB

3 Universal Declaration of Human Rights. New York, NY: United Nations. United Nations General Assembly Resolution 217 A (III) (1948).

4 International Covenant on Economic, Social and Cultural Rights. New York, NY: United Nations. A/ $6316(1966)$.

5 T. Paulson. Epidemiology: a mortal foe. Nature. 2013; 502(7470): $\mathrm{S}_{2}-3$.

6 World Health Organization. Global TB report 2019. Geneva: World Health Organization; 2019. www .who.int/tb/publications/global_report/en/. 
poses to human health is mainly a consequence of the enormous neglect the TB research field has experienced over the past several decades."

This neglect reflects chronic underinvestment in research and development (R\&D). There is a lack of scientific innovation in TB due to insufficient funding by the public sector and limited and diminishing activity by the pharmaceutical industry.

At the 2018 United Nations High-Level Meeting on TB, UN member states committed "to mobilize sufficient and sustainable financing for research, with the aim of increasing overall global investments to US \$2 billion [per year] ... ensuring that all countries contribute appropriately to R\&D." (The $\$ 2$ billion annual target was first set by the Stop TB Partnership in 2006.) An annual survey of TB expenditures by public, philanthropic, private, and multilateral institutions conducted by Treatment Action Group (TAG) over the last fourteen years shows that annual investments in TB R\&D have fallen far short of this $\$ 2$ billion target, never exceeding \$9oo million in any given year. ${ }^{9}$ This points to states' failure to support science, either by failing to directly fund $\mathrm{TB}$ research, or by not putting in place legislative, regulatory, and policy frameworks able to attract investment by other sectors.

In 2017, less than 0.1 percent of the estimated $\$ 97.2$ billion spent on $R \& D$ by the pharmaceutical industry went to TB. ${ }^{10}$ This is the consequence of a biomedical innovation system driven by market returns rather than public health need; any system focused on commercializing innovation for profit will direct few resources to TB and other diseases of poverty. ${ }^{12}$ TAG's data document a clear decline in this already limited TB research spending by pharmaceutical companies and an increasing reliance on the public sector to fund TB R\&D. ${ }^{13}$

7 World Health Organization. Global investments in tuberculosis research and development: past, present, and future. Geneva: World Health Organization; 2017. https://apps.who.int/iris/bitstream/ handle/10665/259412/9789241513326-eng.pdf;jsessionid=1187 DBC99A8 $5 \mathrm{BB}_{54} \mathrm{C}_{1} \mathrm{Cl}_{19} \mathrm{CF}_{2} \mathrm{~B}_{3} 88_{535}$ ? sequence $=1$.

8 UN General Assembly. Political Declaration of the UN High Level Meeting on the Fight against Tuberculosis A/RES/73/3 (October 10, 2018). www.who.int/tb/unhlmonTBDeclaration.pdf.

9 M. Low. 2018 report on tuberculosis research funding trends. New York: Treatment Action Group; 2018. www.treatmentactiongroup.org/content/tbrd2018.

10 Combined, private-sector companies spent less than $\$ 100$ million on TB research in 2017. This is less than 0.1 percent of the $\$ 97.2$ billion EvaluatePharma estimates the pharmaceutical industry spent on R\&D in the same year. See: M. Low. 2018 report on tuberculosis research funding trends. New York: Treatment Action Group; 2018. www.treatmentactiongroup.org/content/tbrd2o18.

1 Despite accounting for 2 percent of healthy life-years lost to disability, TB only receives 0.25 percent of the money spent on medical research annually. See: World Health Organization. Global investments in tuberculosis research and development: past, present, and future. Geneva: World Health Organization; 2017. https:/apps.who.int/iris/bitstream/handle/10665/259412/9789241513326-eng.pdf; jsessionid $=1187 \mathrm{DBC} 99 \mathrm{~A}_{5} \mathrm{BB}_{54} \mathrm{Cl}_{1} \mathrm{C}_{19} \mathrm{CF}_{2} \mathrm{~B}_{3} 88_{53}$ ? sequence $=1$.

12 P. Farmer. Infections and inequalities: the modern plagues. Berkeley: University of California Press; 1999 .

13 In 2017,66 percent of TB research funding came from the public sector compared to 11 percent from private-sector companies (with the remainder made up by philanthropic and multilateral organizations). While governments accounted for 60 percent or more of TB research expenditures in any 
Although public money underwrites most TB research projects, pharmaceutical companies often retain control over research outputs. Responding to this, activists have demonstrated how the public pays three times for TB innovation. ${ }^{14}$ First, to fund the research itself. Second, to purchase resulting technologies at prices set by pharmaceutical companies, which hold intellectual property on publicly funded innovations. And then again when these same companies that benefit from public research dollars deplete public budgets through tax evasion schemes. ${ }^{15}$ When research produces breakthroughs, these tools are priced out of reach or otherwise remain unattainable for most people with TB. This reveals the importance of recognizing access as a cornerstone of the right to science.

\section{2 “ThE RIGHT TO SCIENCE CONNOTES, FIRST OF ALL, A Right OF ACCESS"}

Thus wrote former Special Rapporteur (SR) in the field of cultural rights, Farida Shaheed, in her 2012 report to the Human Rights Council. ${ }^{16}$ Legal scholars such as Lea Shaver have similarly described access as "the touchstone concept of the right," inherent in its earliest formulations, and visible in the way UDHR Article 27 speaks of the right of everyone "to participate in cultural life," "to enjoy the arts," and "to share in scientific advancement and its benefits." ${ }^{17}$

Determining what constitutes access under the right to science is critical to turning this right into an entitlement that individuals can claim, and into a tool that activists can use to hold states accountable for meeting their attendant obligations. Under international human rights law, access is composed of multiple dimensions, and "the dimensions of access require some adaptability from right to right." 18 General Comment No. 14 of the Committee on Economic, Social and Cultural Rights (CESCR) describes access under the right to health as encompassing four domains: nondiscrimination, physical accessibility, economic accessibility

given year over the last decade, there was a steep decline in spending by the pharmaceutical industry during the same period. Industry investments in TB research dropped from a peak of $\$ 145$ million in 2011 to less than \$9o million in 2018. One company - the Japan-based Otsuka Pharmaceuticals accounted for 60 percent of industry expenditures over this period. See: M. Low. 2018 report on tuberculosis research funding trends. New York: Treatment Action Group; 2018. www .treatmentactiongroup.org/content/tbrd2o18.

14 M. Balasegaram. Drugs for the poor, drugs for the rich: why the current R\&D model doesn't deliver. PLoS Speaking of Medicine. February 14, 2014. https://blogs.plos.org/speakingofmedicine/2014/oz/14/ drugs-poor-drugs-rich-current-rd-model-doesnt-deliver/.

15 See, for example: Oxfam. Prescriptions for poverty: drug companies as tax dodgers, price gougers, and influence peddlers. London: Oxfam; 2018. www.oxfam.org/en/research/prescription-poverty.

16 United Nations, General Assembly. Report of the Special Rapporteur in the field of cultural rights, Farida Shaheed: The right to benefit from scientific applications and its progress. A/HRC/20/26 (May 14, 2012). www.ohchr.org/EN/Issues/CulturalRights/Pages/benefitfromscientificprogress.aspx.

17 L. Shaver. The right to science and culture. Wisconsin Law Review. 2010; 121: 122-184 (emphases added).

18 Ibid. 
(affordability), and access to information. ${ }^{19}$ In the $3 \mathrm{AQ}$ framework, accessibility sits alongside the availability, acceptability, and quality of health facilities, goods, and services as an essential element of the right to health in all its forms and at all levels.

In General Comment No. 25, CESCR related the $3 \mathrm{AQ}$ framework to the right to science and added a fifth element: the protection of freedom of scientific research. ${ }^{20}$ The application of the $3 \mathrm{AQ}$ framework to the right to health has greatly clarified the nature of state obligations with respect to access. The analysis of access in General Comment No. 25 also reflects the work of scholars and activists to sketch the dimensions of access under the right in the lead up to CESCR issuing this authoritative legal interpretation. In keeping with one of the foundational principles of international human rights law, access must satisfy the requirement of nondiscrimination (e.g., ICESCR Article 2.2). The treaty language in Article 15 describes scientific progress in terms of both its "benefits" and "applications." This strongly suggests that access extends beyond general knowledge to encompass tangible applications of science. ${ }^{21}$ Similarly, Audrey Chapman has said that the term "benefits" should be understood as including "material benefits," and that a human rights approach requires attention to how these benefits are distributed to disadvantaged communities. ${ }^{22}$ Shaheed condensed these ideas into the powerful statement that "innovations essential for a life with dignity" must be accessible to everyone. ${ }^{23}$

This idea has provided a powerful hook for TB activists seeking to connect people affected by TB to the tangible outputs of science in the form of new drugs, diagnostics, and vaccines. This is familiar territory. The phrase "innovations essential for a life with dignity" contains echoes of the term "essential drugs," provision of which is a core obligation under the right to health. ${ }^{24}$

TB activists have intuited the importance of not narrowly defining access as meaning only material benefits. Just as people with TB need new drugs, scientists need access to data, samples, and compounds. The right, therefore, must encompass the ability of scientists to access the means, methods, and tools of discovery. And both scientists and the public need access to intangible forms of knowledge and

19 Committee on Economic, Social and Cultural Rights. General Comment No. 14, The right to the highest attainable standard of health. E/C.12/2000/4 (August 11, 2000). https://digitallibrary.un.org /record/425041?ln=en.

20 Committee on Economic, Social and Cultural Rights. General comment No. 25 (2020) on Science and economic, social and cultural rights Art. 15.1.b, 15.2, 15.3 and 15.4. E/C.12/GC/25 (April 7, 2020). www.ohchr.org/en/hrbodies/cescr/pages/cescrindex.aspx.

21 L. Shaver. The right to science and culture. Wisconsin Law Review. 2010;121: 122-184.

22 A. Chapman. Towards an understanding of the right to enjoy the benefits of scientific progress and its applications. Journal of Human Rights. 2009;8: 1-36.

23 United Nations, General Assembly. Report of the Special Rapporteur in the field of cultural rights, Farida Shaheed: The right to benefit from scientific applications and its progress. A/HRC/20/26 (May 14, 2012). www.ohchr.org/EN/Issues/CulturalRights/Pages/benefitfromscientificprogress.aspx.

24 Committee on Economic, Social and Cultural Rights. General Comment No. 14, The right to the highest attainable standard of health. E/C.12/2000/4 (August 11, 2000). https://digitallibrary.un.org $/$ record/425041? ln=en. 
information. This idea is represented by the "continuum of access" developed by the American Association for the Advancement of Science (AAAS), which depicts access as stretching from the public on one side to scientists on the other. ${ }^{25}$

Accordingly, TAG has previously framed state obligations to address TB under the right to science in line with Article 15.2 of ICESCR, ${ }^{26}$ which establishes the conservation, development, and diffusion of science as state obligations. By combining all three, Article 15.2 lays out a concept of access that connects state support for science (development) with the equitable distribution of the benefits and applications of scientific progress (diffusion) and efforts to ensure that these benefits are lasting (conservation). In this context, we understand conservation as meaning that the benefits of science are available not only to people alive today, but also to future generations. ${ }^{27}$ We argue that a state that satisfies its obligation to develop science without supporting diffusion and conservation has not created the conditions necessary for access.

\subsection{PARTICIPATION IN SCIENCE IS A PREREQUISITE TO ACCESSING THE BENEFITS OF SCIENTIFIC PROGRESS}

Participation is one of the animating values of the right to science and is directly linked to access. Most obviously, participation in relation to science refers to the ability of scientists to engage in the scientific endeavor. But it also speaks to the ability of nonscientists - including research participants and the intended beneficiaries of science - to have a voice in decision-making about science. ${ }^{28}$ In her 2012 report, Shaheed identifies the participation of individuals and communities in decision-making about science as a key element of the right's normative content. ${ }^{29}$ Participation is so central to the right to science that in General Comment No. 25 CESCR added the word participation to the longform name of the right itself: "Thus, it is the right to participate and to enjoy the benefits from scientific progress and its applications." 30

25 AAAS Science and Human Rights Coalition. Defining the right to enjoy the benefits of scientific progress and its applications: American scientists' perspectives. Washington, DC: American Association for the Advancement of Science; 2013. www.aaas.org/sites/default/files/content_files/ UNReportAAAS.pdf.

26 M. Frick, I. Henry, and E. Lessem. Falling short of the rights to health and scientific progress: inadequate TB drug research and access. Health and Human Rights. 2016; 18(1): 9-23.

27 Ibid

28 For example, General Comment No. 25 para. 9 states that "The right ... cannot be interpreted as establishing a rigid distinction between the scientist who produces science and the general population entitled only to enjoy benefits derived from research conducted by scientists."

29 United Nations, General Assembly. Report of the Special Rapporteur in the field of cultural rights, Farida Shaheed: The right to benefit from scientific applications and its progress. A/HRC/2O/26 (May 14, 2012). www.ohchr.org/EN/Issues/CulturalRights/Pages/benefitfromscientificprogress.aspx.

30 Emphasis added, see para. 11 of Committee on Economic, Social and Cultural Rights. General comment No. 25 (2020) on Science and economic, social and cultural rights Art. 15.1.b, 15.2, 15.3 and 15.4. E/C.12/GC/25 (April 7, 2020). www.ohchr.org/en/hrbodies/cescr/pages/cescrindex.aspx. 
Participation protects people, especially marginalized populations, against scientific misconduct and the possible harms of technological development. It also creates opportunities for communities to advocate for research that addresses their needs and priorities. In order for this advocacy to be successful, communities must first find firm footing and representation among the many actors involved in doing science. In TB research, modeling the HIV approach, this representation has often advanced through community advisory boards (CABs). These groups are comprised of research-literate community members including people with $\mathrm{TB}$, survivors of TB, affected family, local health activists, religious leaders, and other stakeholders. ${ }^{31}$ CABs operate in an advisory capacity to research networks and sponsors of clinical trials and seek to raise community perspectives within funding bodies and scientific fora. These perspectives span issues of trial design, study conduct, results dissemination, and concerns about access to investigational technologies. ${ }^{32}$

When a $\mathrm{CAB}$ proposes a new study, objects to the exclusion of a particular population from a trial, questions the utility of a study procedure, or poses a research question to be examined, it is performing an important act of translational advocacy. This connects the objectives of scientists with interests vital to the communities for whom, and in which, research is conducted. If done well, the result is a dialogue between scientists and community representatives that produces value for both sides. For this dialogue to unfold, scientists themselves must recognize community expertise for what it is: a different way of approaching knowledge production, but one with equal legitimacy. More often, TB researchers have treated CABs either instrumentally (one common misconception is that community advisors exist only to promote the enrollment of participants into clinical trials), or have viewed them as stakeholders to placate before the real work of science can get underway. Confronting this dynamic has required $\mathrm{CAB}$ members to build their own knowledge of research in order to effectively advocate for community priorities with scientists on their own terms.

The experiences of two CABs coordinated by TAG - the Global TB Community Advisory Board (Global TB CAB) and the Community Research Advisors Group (CRAG) - illustrate how community participation has changed the direction of TB research. The Global TB CAB is a group of community-based activists from HIV and TB networks around the world that engages product developers, pharmaceutical companies, and public institutions conducting clinical trials of TB drug regimens, diagnostics, and vaccines. ${ }^{33}$ The CRAG advises TB research conducted by the U.S. Centers for Disease Control and Prevention (CDC). Both groups have employed the early review of clinical trial protocols to influence studies before they begin. In

${ }^{31}$ A. DeLuca, E. Lessem, D. Wegener, L. Ruiz Mingote, M. Frick, D. Von Delft. The evolving role of advocacy in tuberculosis. Lancet Respir Med. 2014; 2(4): 258-259.

$3^{2}$ Ibid.

33 For more about the Global Tuberculosis Community Advisory Board, see: TBonline.info. http:// tbonline.info/tbcab/. 
2016, the Global TB CAB and CRAG examined their feedback on protocols for thirteen late-stage $\mathrm{TB}$ drug trials to identify common areas of concern and document the impact of community review. They found that study protocols routinely failed to address the following scientific and ethical concerns of high priority to communities: plans for results dissemination; post-trial access to investigational products; adequate composition (or even presence) of control arms; use of non-stigmatizing language in study documents; and the appropriate inclusion of key populations disproportionately impacted by TB, including people living with HIV (PLHIV), children, adolescents, and pregnant women. ${ }^{34}$

Community activists have made partial, but significant, progress on all of these fronts. For example, the CRAG successfully advocated with investigators planning a phase III trial of a shorter TB regimen to broaden the eligibility criteria to include PLHIV and adolescents. ${ }^{35}$ The CRAG argued that since TB incidence is higher in young people and in PLHIV, it is important to assess new drug regimens in these populations. In another instance, the Global TB CAB won changes to the protocol of the STREAM study - at the time the largest drug-resistant TB treatment trial in history - by sharing concerns about the choice of the control arm in relation to the global standard of care. ${ }^{36}$ Following this interaction, the study's investigators launched a robust program of community engagement at trial sites and supported the start-up of several local CABs. ${ }^{37}$

What motivates the work of the Global TB CAB, CRAG, and other TB community advisory structures is the hard-earned knowledge that participation in science is a prerequisite to accessing the benefits of scientific progress. The link between participation and access is rooted in two fundamental components of participation: inclusion and reciprocity.

\subsubsection{Inclusion: Nothing About Us without Us}

In global health movements, inclusion is often expressed through the organizing slogan "nothing about us without us!" The right of people affected by a disease to participate in all decisions concerning their lives has been a core tenant of global health advocacy since the formulation of the 1983 Denver Principles. Rejecting the

34 L. McKenna, M. Frick, and D. Namutamba, et al. Community advisory boards on repeat: what's missing from TB clinical trials protocols. Paper presented at: 21st International AIDS Conference; Durban, South Africa; July 18-22, 2016.

35 S. Dorman, P. Nahid, E. Kurbatova, et al. High-dose rifapentine with or without moxifloxacin for shortening treatment of pulmonary tuberculosis: study protocol for TBTC Study 31 /ACTG A5349 phase 3 clinical trial. Contemp Clin Trials. 2020; 80: 105938.

36 M. Frick. Sound science of redesigned STREAM trial (originally published as "Fool's errand: the sloppy science of the MDR-TB STREAM trial"). Tagline. 2014; 21(1): 14-15. www.treatmentactiongroup.org tagline.

37 See reflections by Ezio Tavora in M. Frick and L. McKenna. Sound off: three activists reflect on community victories and priorities in TB research, an interview with Sarah Mulera, Ezio Tavora, and Wim Vandevelde. Tagline. 2019; 26(1): 9-11. www.treatmentactiongroup.org/tagline. 
passivity of labels such as "victims," "patients," or "subjects," a coalition calling itself People with AIDS laid out a foundational vision of self-determination, autonomy, and empowerment. ${ }^{38}$ This vision included the right of people with AIDS to "be involved at every level of decision-making;" to "be included in all AIDS forums with equal credibility as other participants;" and to receive "full explanations of all medical procedures and risks, to choose or refuse their treatment modalities, to refuse to participate in research without jeopardizing their treatment, and to make informed decisions about their lives."39

The standard of inclusion articulated in the Denver Principles has become the guide star for an epistemic community working to ensure that global health centers people affected by HIV, TB, and other illnesses. In the context of HIV/AIDS programs, this philosophy is called the "greater involvement of people with AIDS" (GIPA). $4^{\circ}$ In the setting of research, an odd kinship of grassroots activists, CABs, funders, scientists, and clinical trial participants has sought to enshrine "good participatory practice" (GPP) as an essential part of ethical medical research. Today, there are guidelines on GPP for HIV prevention research, TB drug trials, $\mathrm{TB}$ vaccine research, and trials on emerging pathogens. ${ }^{41} 4^{2} 4344$ These guidelines provide researchers with a roadmap for meaningfully engaging communities at each stage of a clinical trial. GPP complements existing regulatory standards such as Good Clinical Practice. It sits alongside - though does not replace - other participatory research methods, including participatory action research and communitybased participatory research. ${ }^{45}$

Participation in science also functions as a prerequisite for accessing the benefits and applications of scientific progress. While the Denver Principles articulated the right of People with AIDS to decline research participation - recalling the bioethical precepts of autonomy, and free and informed consent - just as often the fight is about

$3^{8}$ Advisory Committee of the People with AIDS. The Denver Principles. Denver: People with AIDS; 1983. http://data.unaids.org/pub/externaldocument/2007/gipa1983denverprinciples_en.pdf.

39

$4^{\circ}$ UNAIDS. The Greater Involvement of People Living with HIV (GIPA): UNAIDS Policy Brief. Geneva: UNAIDS; 2007. http://data.unaids.org/pub/briefingnote/2007/jc1299_policy_brief_gipa.pdf.

${ }^{41}$ AVAC. Good participatory practice: guidelines for biomedical HIV prevention trials, end edition. New York: AVAC; 2011. https://www.avac.org/good-participatory-practice

42 Critical Path to TB Drug Regimens. Good participatory practice guidelines for TB drug trials. Washington, DC: Critical Path to TB Drug Regimens; 2012. www.cptrinitiative.org/downloads/ resources/GPP-TB\%20Oct1\%202012\%2oFINAL.pdf.

43 Aeras. Good participatory practice guidelines for TB vaccine research. Washington, D.C.: Aeras; 2017. www.avac.org/resource/good-participatory-practice-guidelines-tb-vaccine-research-2017.

44 World Health Organization. Good participatory practice guidelines for trials of emerging (and reemerging) pathogens that are likely to cause severe outbreaks in the near future and for which few or no medical countermeasures exist. Geneva: World Health Organization; 2016. www.avac.org /resource/good-participatory-practice-guidelines-trials-emerging-and-re-emerging-pathogens $\% \mathrm{C}_{2} \%$ Ao-are.

45 K. MacQueen and J. Auerbach. It is not just about "the trial": the critical role of effective engagement and participatory practices for moving the HIV research field forward. J Int AIDS Soc. 2018; 21 $\left(\mathrm{S}_{7}\right)$ : e25179. 
gaining inclusion in the scientific agenda. The systematic exclusion of certain groups from research is a form of marginalization that reinforces disparities in which some populations shoulder a greater burden of TB than others. Activists have shown how TB clinical trials favor enrollment of "typical" TB patients with easier-to-treat forms of disease. ${ }^{4^{6}}$ As a result, people with complicating comorbidities (e.g., HIV, diabetes) or severe disease manifestations (e.g., TB meningitis) are left out of trials. Other groups such as children, adolescents, and pregnant women are excluded out of a misplaced desire to protect vulnerable populations from harm.

In actuality, research protection interpreted as exclusion amplifies TB-related harms. Evidence-based guidelines cannot be made in the absence of evidence that an intervention works in a particular population. Some of the populations most vulnerable to TB are either not represented in normative guidance produced by $\mathrm{WHO}$, or must wait years for well-established interventions to be recommended for their use. The CRAG and TB CAB mobilized to increase the inclusion of pregnant women in TB research, arguing that the risks inherent to research must be weighed against potential benefits as well as the predictable harms of not conducting research in pregnant women. "In the absence of research, each pregnant woman treated for TB becomes an individual experiment," CAB members argued. "Approaching each pregnant woman with $\mathrm{TB}$ as an experiment with a sample size of one precludes conducting the systematic research needed to produce the generalizable knowledge necessary to improve clinical care for all pregnant women with TB." ${ }^{47}$ Rather than policies of blanket exclusion, the TB CAB and CRAG argued that researchers should presume pregnant women eligible for research participation and then provide specific ethical and scientific justification to support ineligibility. Thus, participation as inclusion constitutes an essential condition by which states can deliver on their obligation to provide all people with access to innovations essential for a life with dignity.

$\mathrm{TB}$ activists are not alone in confronting the unfairness through which exclusion from research results in the benefits of science accruing to some groups over others. AIDS activists have pointed out that HIV treatment and cure trials enroll more white gay men than women, transgender people, or people of color. ${ }^{4} 49$ That HIV and TB activists framed research inclusion as an issue of justice is thanks to the work of feminists and communities of color in the United States to secure policies from the

46 Stillo, Jonathan, Mike Frick, and Yali Cong. "Upholding Ethical Values and Human Rights on New Frontiers of TB Care and Control". The International Journal of Tuberculosis and Lung Disease. 2020. 24(1) pp. 48-56.

47 L. McKenna, M. Frick, D. Namutamba, et al. Community advisory boards on repeat: what's missing from TB clinical trials protocols. Paper presented at: 21st International AIDS Conference; Durban, South Africa; July 18-22, 2016.

$4^{8}$ M. Curno, S. Rossi, I. Hodges-Mameletzis, et al. A systematic review of the inclusion (or exclusion) of women in HIV research. J Acquir Immune Defic Snydr. 2016; 71(2): 181-188.

49 J. Castillo-Mancilla, S. Cohn, S. Krishnan, et al. Minorities remain underrepresented in HIV/AIDS research despite access to clinical trials. HIV Clin Trials. 2014; 15(1): 14-26. 
National Institutes of Health and Food and Drug Administration (FDA) requiring the inclusion of women and racial minorities in clinical trials, and the analysis of data by gender and race. ${ }^{\circ}$

\subsubsection{Reciprocity: From "Do No Harm" to Repairing Harm}

Alongside inclusion, the concept of reciprocity is important for understanding state obligations with respect to participation under the right to science. Bioethicists have defined reciprocity as "returning goods in proportion to those received and compensating those who have been harmed." ${ }^{11}$ Diego Silva and colleagues have used this notion of reciprocity to examine state obligations to people with TB who must endure periods of involuntary isolation or detention to limit the risk of transmission to others. They argue that reciprocity is more than a "thank you;" it is "a means of society and the state accepting responsibility for the conditions that have led to infection and disease from TB." 5253 To the extent TB is a disease of poverty, the state has an obligation to compensate people with TB for harm caused by the state's failure to ameliorate the conditions that give rise to TB and disproportionately distribute its harms.

In the context of research, that is, development under the right to science, the concept of reciprocity helps elucidate rights and responsibilities. Individuals who enroll in clinical trials assume real risk in exchange for benefits that are by definition unknown and not guaranteed. Communities that host research provide a valuable social good to scientific endeavors that are often led by scientists or pharmaceutical companies in the Global North. Through such participation, these individuals and communities create the conditions under which science advances. Recognizing a right to enjoy the benefits of scientific progress creates the possibility of reciprocity in this exchange.

To borrow Silva's reasoning that reciprocity creates the grounds for acknowledging state responsibility to repair harm: the clear connection between the lack of support for TB R\&D and the continued toll that TB exacts further compels states to support the conservation, development, and diffusion of science and its benefits. Supporting the purposive development of science and technology for TB is a way for states to address harms arising from the inadequate tools and lack of innovation underlying the TB epidemic. This responsibility is shared by all states. As Cristian Timmermann points out, it is hardly forward-thinking to treat one part of the world

$50 \mathrm{~K}$. Baird. The new NIH and FDA medical research policies: targeting gender, promoting justice. J Health Polit Policy Law. 1999; 24(3): 531-565.

51 D. Silva, A. Dawson, and R. Upshur. Reciprocity and ethical tuberculosis treatment and control. Bioethical Inquiry. 2016; 13: 75-86. See also: L. Becker. Reciprocity. New York: Routledge \& Kegan Paul Ltd.; 1986.

52 D. Silva, A. Dawson, and R. Upshur. Reciprocity and ethical tuberculosis treatment and control. Bioethical Inquiry. 2016; 13: 75-86.

53 A. Viens, C. Bensimon, R. Upshur. Your liberty or your life: reciprocity in the use of restrictive measures in contexts of contagion. Bioethical Inquiry. 2009; 6(2): 207-217. 
as that which does science and another as that which receives it: "There is a huge amount of unacknowledged reciprocity for inventions placed in technologydependent societies. Developers of technologies gain many insights from their users." ${ }^{54}$ An ethic of reciprocity arises from the participation of individuals in research; this contribution creates an obligation by states to ensure that the benefits of research are equitably shared, again linking participation and access.

\subsection{CREATING ACCOUNTABILITY THROUGH ADVOCACY}

How have TB advocates used the above framework to hold governments accountable to meeting their obligations under the right to science? Over the past three years, TAG has sought opportunities to promote knowledge of the right to science within the UN system and among fellow advocates. As is clear from the above analyses of participation and access, the right holds tremendous potential for giving new impetus to the global TB response by focusing state attention on the development of new tools and interventions with meaningful community participation and through means that ensure the equitable diffusion of these advancements. Since human rights are interrelated, interdependent, and indivisible, the right to science also provides a new lens through which activists can frame issues they have been trying to change for decades.

\subsubsection{Working with United Nations Mechanisms}

One immediate barrier to realizing this potential is the absence of writing that analyzes specific issues using a right to science lens or attempts to take such analyses from international law into the realm of domestic law and local health policy. Therefore, TAG identified several UN mechanisms that would provide the opportunity to analyze TB as a human rights issue under the right to science.

The UN system provides several channels through which human rights violations can be brought to light. One mechanism is the Universal Periodic Review (UPR), which regularly reviews the human rights record of each member state and which allows for parallel submissions by civil society that feed into the official UPR documentation for each country. TAG wrote submissions for the third cycle UPR of three countries: China (2018), ${ }^{55}$ Mexico (2018), ${ }^{56}$ and the United Arab Emirates (2017). ${ }^{57}$

54 C. Timmermann. Sharing in or benefitting from scientific advancement? Sci Eng Ethics. 2014; 2O(1): 111133 .

55 Treatment Action Group. Submission to Human Rights Council Universal Periodic Review (Third Cycle) of the People's Republic of China. New York: Treatment Action Group; 2018. http://treatmen tactiongroup.org/content/tb-human-rights-and-universal-periodic-review.

${ }^{5}$ Treatment Action Group. Submission to Human Rights Council Universal Periodic Review (Third Cycle) of Mexico. New York: Treatment Action Group; 2018. http://treatmentactiongroup.org/con tent/tb-human-rights-and-universal-periodic-review.

57 Treatment Action Group. Submission to Human Rights Council Universal Periodic Review (Third Cycle) of the United Arab Emirates. New York: Treatment Action Group; 2018. http://treatmentac tiongroup.org/content/tb-human-rights-and-universal-periodic-review. 
TAG's United Arab Emirates (UAE) UPR submission grew from statements by migrant workers deported from the UAE for signs of TB based on a flawed diagnostic algorithm deployed in mandatory medical exams for work permit applications. We wrote a succinct analysis of how the public health policies governing TB screening and the laws directing its application in immigration proceedings failed to meet international scientific and human rights standards. TAG delivered an oral intervention at the UPR pre-session in Geneva, and has since engaged with the special procedures mechanisms to push for legal protections against deportation on the basis of TB or other health status. The issue of TB and migrant health screening in the UAE lent itself well to an analysis spanning the diffusion of scientific progress (i.e. TB screening according to global scientific standards) and related rights such as health, information, and nondiscrimination. Through this analysis, TAG hoped to showcase how the right to science contributes to an understanding of the rights of migrants with the explicit goal of influencing UN bodies that may not recognize the right to science as relevant to their missions.

For the UPR of China, TAG's submission analyzed China's response to drugresistant TB (DR-TB), showing how in responding to its DR-TB epidemic, China had failed to both diffuse existing tools for confronting DR-TB to all people in need and develop improved tools through investments in research. As a country that heavily restricts civil society activities nationally, and aims to limit the activity of global civil society with regards to its human rights record and conduct, China exemplified the connection of the right to science to the right to participation, as well as to freedoms of association and assembly.

TAG's experience raising right to science issues in the third-cycle UPR has led to the realization that even within the UN system there remains a great distance to travel before the right to science gains wide recognition and acceptance. In particular, TAG has faced challenges disentangling the right to science from the right to health, which many observers may find more immediately applicable to the context of TB. One case in point: despite TAG's UPR submission for China supplying a right to science analysis, in the summary of stakeholder submissions, TAG's submission was mentioned under the subheading of right to health, without any mention of the right to science.

\subsubsection{Linking Conservation, Development, and Diffusion}

TAG has called out insufficient funding for TB research as a failure of governments to live up to their obligation to develop science..$^{8} 59$ One concrete solution activists have proposed to increase state attention to TB R\&D is the Life Prize. The initiative

$5^{8}$ M. Frick. Funding for tuberculosis research - an urgent crisis of political will, human rights, and global solidarity. Int J Infect Dis. 2017; 56: 21-24.

59 M. Frick, I. Henry, E. Lessem. Falling short of the rights to health and scientific progress: inadequate TB drug research and access. Health and Human Rights. 2016; 18(1): 9-23. 
seeks to foster open collaboration among different companies, drug developers, and governments to develop a one-month regimen for treating TB that is affordable and available to all. To accomplish this, the Life Prize would deploy three mechanisms: pull incentives that reward early-stage research on compounds through milestonebased prize funds; a pool for data and intellectual property so that compounds held by different companies can be developed together without patent barriers; and push incentives (e.g., grant funding) for the clinical development of candidate regimens. ${ }^{60}$ Money for the prize funds and grants would come from governments, a form of international collaboration encouraged by Article 15.4 of ICESCR. ${ }^{61}$

By combining push, pool, and pull mechanisms, the Life Prize seeks to separate the costs of research and development from the prices and sales volumes of final products. ${ }^{62}$ In doing so, it would promote the affordability of medicines by eliminating the need of manufacturers to recoup R\&D investments with high prices and patent-protected monopolies. In spurring $\mathrm{R} \& \mathrm{D}$ without relying on market-based incentives, the Life Prize creates the conditions for a more equitable approach to innovation, one that sees scientific development and widespread diffusion as equal, complementary goals.

The Life Prize also provides a useful framework for thinking through the conservation of science in the context of infectious diseases. One pernicious debate circulating in the TB field pits antibiotic stewardship aimed at preventing drug resistance against universal access to medicines. This framing arises from the real urgency of confronting DR-TB and the well-intentioned desire to stem drugresistance by limiting the improper use of TB medicines. In effect, however, this stance frames conservation not in terms of access, but exclusion. In doing so, it loses sight of the pressing reality that only one in four people who develop DR-TB in any given year have access to treatment. ${ }^{63}$ It also obscures the roots of DR-TB, blaming patients for nonadherence to regimens or prescribers for antibiotic misuse. Scientific evidence points in another direction. Sequencing of clinical isolates from DR-TB outbreaks suggests "drug-resistant strains circulating today reflect not only

6o G. Brigden, J. Castro, L. Ditiu, et al. Tuberculosis and antimicrobial resistance - new models of research and development needed. Bull World Health Organ. 2017; 95(5): 315 .

61 "The States Parties to the present Covenant recognize the benefits to be derived from the encouragement and development of international contacts and co-operation in the scientific and cultural fields." Article $\mathbf{1 5 . 4}$ of the International Covenant on Economic, Social and Cultural Rights. New York, NY: United Nations. A/6316 (1966).

62 It is interesting to note that the concepts behind the Life Prize - namely, separating R\&D incentives from sales volumes and prices - are contained in para. 62 of General Comment No. 25: "Firstly, to counter distortions of funding associated with intellectual property, States should provide adequate financial support for research that is important for the enjoyment of economic, social and cultural rights, either through national efforts or, if necessary, by resorting to international and technical cooperation. States could also resort to other incentives, such as so-called market entry rewards, which delink remuneration of successful research from future sales, thus fostering research by private actors in these otherwise neglected fields."

63 World Health Organization. Global TB report 2019. Geneva: World Health Organization; 2019. www .who.int/tb/publications/global_report/en/. 
vulnerabilities of current TB control efforts but also those that date back 50 years." ${ }^{4}$ Instead of recognizing this historical legacy, when treatment fails, as it often does in $\mathrm{TB}$, the assumption is that patients are nonadherent while medicines are always efficacious. In actuality, many existing TB drugs have little efficacy, and many adherence challenges stem from the toxic side effects of the medicines themselves or the long duration of treatment. ${ }^{6}$ TB activists have tried to shift this narrative of individual blame by keeping the onus on governments to plug the glaring treatment access gaps that deny so many people with DR-TB effective therapy.

TB researchers and clinicians Jennifer Furin and Madhukar Pai have called out the "tension between wanting to 'protect the new drugs' as opposed to protecting the lives of patients, with the drugs being restricted in order to purportedly preserve their efficacy." 66 This perverse logic is so endemic in the TB field that within hours of the FDA approving a new regimen with novel antibiotic pretomanid to treat the most resistant strains of TB in 2019 there was talk of "saving" pretomanid from resistance. Heralding the FDA approval, the director of the largest NGO provider of TB technical assistance globally said: "Responsible use of pretomanid-based regimens needs to be ensured. After all, we have to protect our new medicines!" ${ }^{77}$ TB activists responded differently. They pointed out that pretomanid was developed with public and philanthropic funding and was therefore a "public good." In addition, while acknowledging critical research gaps precluding wide use of pretomanid, activists called for its evidence-based introduction for patients in need according to a set of minimum terms. ${ }^{68}$ Activists also called for additional research on the drug, particularly regarding its safety profile and use in special populations such as children.

The example of pretomanid, and other newer TB drugs, underscores the need for a new model of R\&D, one able to link scientific development with equitable diffusion. One in which access is understood as part of conservation rather than anathema to it. The Life Prize would address the real need to safeguard the efficacy of news drugs against the development of drug-resistance without trading access for conservation. Regimens developed by the Life Prize would be licensed to

${ }^{64}$ K. Cohen, T. Abeel, and A. McGuire, et al. Evolution of extensively drug-resistant tuberculosis over four decades: whole genome sequencing and dating analysis of Mycobacterium tuberculosis isolates from KwaZulu-Natal. PLoS Medicine. 2015; 12(9) :d1oo188o.

${ }_{5}$ M. Frick, I. Henry, and E. Lessem. Falling short of the rights to health and scientific progress: inadequate TB drug research and access. Health and Human Rights. 2016; 18(1): 9-23.

66 M. Pai and J. Furin. Tuberculosis innovations mean little if they cannot save lives. eLife. 2017; 6: e25956.

67 KNCV Tuberculosis Foundation. FDA approval of BPaL regimen an important breakthrough in TB control. August 14, 2019. www.kncvtbc.org/en/2019/o8/14/fda-approval-of-bpal-regimen-an-importantbreakthrough-in-tb-control/.

68 These terms included full transparency in the licensing agreement between the developer (TB Alliance) and the manufacturer (Mylan), broad registration in countries, pre-approval access for patients without alternative treatment regimens, and a low global access price of $\$ 1 /$ day. See: Treatment Action Group. Statement from Treatment Action Group on US FDA approval of pretomanid. August 14, 2019. www.treatmentactiongroup.org/content/statement-treatment-actiongroup-us-fda-approval-pretomanid. 
manufacturers, on a nonexclusive basis, with the terms of the license setting quality standards and expectations for pharmacovigilance. ${ }^{69}$ Unfortunately, governments have not yet stepped forward to fund this proposed model.

\subsubsection{Upholding the Right to Science through Strategic Litigation}

One accountability tactic that has not been tried in TB is litigation on behalf of an individual claiming the state has failed to uphold their right to enjoy the benefits of scientific progress. Citing the lack of court cases in which individual petitioners invoke the right to science, Leslie London et al. argue that the right "does not entitle individuals to direct enforceable benefits of scientific progress" by, for example, compelling a state to develop a new drug to treat DR-TB. ${ }^{70}$ In their view, the right to science is realized collectively: people are entitled to the adoption of legislative and policy frameworks aimed at making the benefits of scientific progress available and accessible..$^{71}$

It may be premature to conclude that the right to science is not individually actionable when the justiciability of the right has not been thoroughly tried and tested. As normative consensus on the meaning of the right builds, and as activists, lawyers, and governments become more familiar with entitlements and obligations under Article 15, its potential use in individual litigation will only grow. Even now, it does not require a great deal of imagination to envision how petitioners could make claims under the right to science to argue that states have failed to meet their obligations to conserve, develop, and diffuse the benefits of scientific progress in the context of specific public health emergencies.

As an illustrative exercise, one can read the right to science into existing cases that cite the rights to health or life to argue that an individual or group has a right to access prevention or treatment. Two examples concerning TB come from recent court cases in India. In the first, the Indian Supreme Court directed the government's national TB program to replace the prevailing thrice-weekly administration of TB medicines with daily administration of fixed-dose combination tablets..$^{72} 73$ The ruling followed a public interest litigation filed by physician Raman Kakkar, who had documented that giving TB treatment three times a week (a practice that

69 G. Bridgen. Innovative funding mechanisms for TB R\&D: the ${ }_{3} \mathrm{P}$ project. Presentation at: World Health Organization Global Taskforce on TB Research and Development. Geneva, Switzerland; December 2019 .

$7^{\circ}$ L. London, H. Cox, and F. Coomans. Multidrug-resistant TB: implementing the right to health through the right to enjoy the benefits of scientific progress. Health and Human Rights. 2016; 18(1): $25-41$.

71 Ibid.

72 Dr. Raman Kakar v. Union of India And Anr., Writ Petition (Civil) No. 604 of 2016, Supreme Court of India, Order dated January 23, 2017.

73 V. Dhivan, V. Johari, K. Bhardwaj. Legal environment assessment for TB in India. Chennai: REACH; 2018. www.reachtbnetwork.org/wp-content/uploads/2018/og/REACH-CRG-LEA-2o18-FullVersion.pdf. 
set apart India from global guidelines recommending daily pill taking) resulted in higher rates of treatment failure by making it difficult for patients to adhere to treatment. ${ }^{74}$ In his complaint to the court, Kakkar described the thrice-weekly protocol as "unscientific" and linked it to deaths among TB patients in his district of Faridabad. ${ }^{75}$ Through a combination of his own systematic research and an appeal to international scientific standards, Kakkar argued that the Government of India had failed to keep its TB treatment policies aligned with evolving evidence on what constitutes the highest attainable standard of care.

The second example is one of the most prominent court cases concerning TB in recent years. Kaushal Tripathi, the father of a young woman with extensively drugresistant tuberculosis (XDR-TB), sued a public hospital so that his daughter, Shreya Tripathi, could access a new TB drug, bedaquiline. ${ }^{76}$ First diagnosed with TB in 2013, Shreya likely developed XDR-TB after years of ineffective treatment following a series of incorrect diagnoses. By 2017, the TB strain threatening Shreya's life was resistant to almost every available drug. Facing the end of her life, Shreya and her father traveled from their home in Patna to the Lal Ram Sarup TB Hospital (LRS) in New Delhi, where bedaquiline was available under a conditional access program run by the Indian government at six public hospitals throughout the country. The hospital declined to treat Shreya with bedaquiline, citing a condition of the program: that patients demonstrate legal domicile in the location of the clinic. ${ }^{77}$ With her official residence registered as Patna, Shreya was ineligible to receive bedaquiline in Delhi.

Represented by the Lawyers Collective, Kaushal Tripathi sued LRS for access to bedaquiline for his daughter, arguing that denial of treatment was unconstitutional based on Shreya's fundamental rights to health and life. LRS authorities argued that the TB sickening Shreya was so resistant that it was impossible to construct a sufficiently strong regimen of other TB drugs. ${ }^{78}$ Under these circumstances, giving Shreya bedaquiline would create the opportunity for her strain of TB to develop resistance to the drug - resistance that could spread to others in the community. The efficacy of bedaquiline for other people would thus be "lost." Amicus curiae

74 Press Trust of India. SC asks government to implement new TB protocol. Press Trust of India. January 9, 2017. www.ptinews.com/news/8272011_SC-asks-Centre-to-implement-new-TB-protocol.html.

75 R. Kakar. SC abolishes thrice weekly dose; restores daily dose protocol in TB across India. Journal of Research in Medical Education and Ethics. 2017; 7(1): 1-2.

$7^{6}$ V. Dhivan, V. Johari, and K. Bhardwaj. Legal environment assessment for TB in India. Chennai: REACH; 2018. www.reachtbnetwork.org/wp-content/uploads/2018/o9/REACH-CRG-LEA-2018-FullVersion.pdf.

77 Menaka Rao. A domicile rule is preventing an 18-year-old girl from getting a life-saving TB drug. Scroll.in. January 6, 2017. https://scroll.in/pulse/826005/a-domicile-rule-is-preventing-an-18-year-oldgirl-from-getting-a-life-saving-tb-drug.

$7^{8}$ Affidavit on behalf of respondent no. 1 (Lal Ram Sarup TB Hospital) to the Delhi High Court re. the case of Kaushal Kishore Tripathi v. Lal Ram Sarup Hospital \& Ors., Writ Petition (Civil) No. 11879 of 2016. (Electronic copy on file with authors). 
submitted by a prominent $\mathrm{TB}$ doctor argued the opposite: that the dilemma between saving drugs versus saving lives is a false choice. ${ }^{79}$ In order to protect the public from XDR-TB, the hospital needed to give Shreya bedaquiline as a matter of urgency. The most effective way to stop the spread of $\mathrm{TB}$ is to provide treatment, since once someone starts effective therapy the bacterial count in the body drops and onward transmission is less likely.

In a settlement between parties, the government agreed to grant Shreya access to bedaquiline and "to make clear that domicile or residence of the patient is not a criterion for the eligibility of bedaquiline for its administration." ${ }^{\circ}$

Shreya's XDR-TB was cured, but the access delays proved fatal. By the time Shreya received bedaquiline, her lungs were irreparably damaged; she passed away in October 2018 at the age of nineteen. The loss of Shreya's life is a painful demonstration of how restrictive government access policies turn people with treatable XDR-TB into terminally ill patients by denying them access to new drugs saved for use by future others. The public health goal of sparing drugs from resistance becomes an imperative setting conservation against access. Recognizing a right to science would shift this frame by positioning conservation as one obligation of governments on the same plane of concern as other dimensions of access, including the development and diffusion of scientific progress and its benefits.

\subsection{THE RIGHT TO SCIENCE: FUTURE PROMISE AND POTENTIAL}

If everyone has the right to enjoy the benefits of scientific progress and its applications then this enjoyment must ultimately be fought for, not just in courts but also in communities. Advancing the critical community education and mobilization required to turn the right to science from an underappreciated normative framework into a genuine tool for accountability will not be easy. Looking back at the quotes opening this chapter, and considering the above analyses, we are surprised that this right remains so under-utilized in global health advocacy. While still largely unreferenced in global public health, the right to science is slowly shrugging off its label of being a "forgotten human right," as described by Audrey Chapman in 2009. ${ }^{81}$ However, this emergent awareness has traveled farther in academic circles than among civil society and human rights practitioners.

In part, this may reflect the structure of the international human rights system. While the international covenants and UN bodies offer many entry points for

79 Amicus curiae submitted by Dr. Jennifer Furin (Harvard Medical School, Boston, USA) to the Delhi High Court re. the case of Kaushal Kishore Tripathi v. Lal Ram Sarup Hospital \& Ors., Writ Petition (Civil) No. 11879 of 2016. (Electronic copy on file with authors).

8o Kaushal Kishore Tripathi v. Lal Ram Sarup TB Hospital \& Ors., Delhi High Court, Writ Petition (Civil) No. 11879 of 2016, Order dated January 20, 2017. http://delhihighcourt.nic.in/dhcqrydisp_o.asp $? \mathrm{pn}=11539 \& \mathrm{yr}=2017$.

81 A. Chapman. Towards an understanding of the right to enjoy the benefits of scientific progress and its applications. Journal of Human Rights. 2009; 8: 1-36. 
advocating for human rights, the nature of the system can encourage specialization. Thus advocates fluent in the right to health rarely connect these issues to the right to science. Many may have never heard about the right to science before; even among scientists whose work incorporates human rights analysis, the right to science is not well-known. This is one reason why the right to health remains the trusted analytical framework for advocacy in the realm of global health, even though the right to science may be able to make more direct claims regarding the accessibility of innovations. CESCR's issuance of General Comment No. 25 will draw greater attention by states and civil society to the right to science. We hope that it will, like General Comment No. 14 on the right to health (2000), yield new avenues for action and accountability, while enabling scholars and practitioners to begin to disentangle the right to science from the right to health.

Whether this attention leads to litigation, and whether the right to science joins the right to health as a tool for increasing access to medicines and other innovations essential for a life with dignity, will depend on mobilizing communities around the human rights dimensions of science. This will require dedicated efforts to raise awareness of the right among communities and translate its entitlements into actionable rights claims. Through efforts by TAG and other civil society actors, the right is slowly gaining more recognition in the TB response. For instance, the 2018 Declaration of the Rights of People Affected by Tuberculosis includes the right to science. $^{82}$ Yet even this community document, in its aim to appeal to an international audience and maintain broad applicability, uses high-level language that will require the development of additional resources to bring the concepts into local contexts so that the right to science may become a tangible form of knowledge and thus community power. Herein lies the responsibility of scholars to translate academic work on the right to science into persuasive arguments and accessible language that activists can use to create tools to turn the right from a set of promises on paper into entitlements claimed, contested, and fulfilled.

The idea of promises - which can be broken or fulfilled, pursued or abandoned is an instructive angle from which to think about the future conjoining of science, human rights, and TB. Bharat Venkat has said that the always-present possibility of drug-resistance, relapse, or reinfection after TB treatment means that cures for TB "might be better conceived of as endings lacking finality ... a promise rather than a rupture ... a promise that, like all promises, can be broken." 83 Understanding TB cure as contingent rather than assured acknowledges that scientific progress cannot be taken for granted. The TB of today is different from the TB of yesterday. The scientific advances ushered in by germ theory, the microscope, the antibiotic revolution, the mapping of the human and Mycobacterium tuberculosis genomes,

82 TB People. Declaration of the rights on people affected by tuberculosis. Geneva: Stop TB Partnership: May 2019. www.stoptb.org/assets/documents/communities/FINAL\%2oDeclaration\%

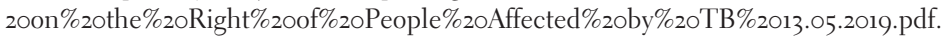

83 B. Venkat. Cures. Public Culture. 2016; 28(3): 475-497. 
and other leaps forward in knowledge have given us new tools and vantage points from which to fight TB.

Our tools will need to keep evolving. Keeping the promise of cure alive will always depend on science progressing. Writing nearly twenty years ago, Paul Farmer observed: "even as our biomedical interventions become more effective, our capacity to distribute them equitably is further eroded." ${ }^{4}$ If we can share the fruits of scientific advancement more equitably in the future than we have in the past, then we may move closer to fulfilling the promise of lasting cure. Promises can be broken, but human rights must be fulfilled. The right to science has given individuals confronting TB a way to bring together the development, diffusion, and conservation of scientific progress in a unified vision for ending this deadly epidemic.

\subsection{ADDENDUM - THE RIGHT TO SCIENCE AND COVID-19 - APRIL 2020}

We began revising this chapter as the COVID-19 pandemic reached its staggering scale, shutting down societies across the globe. Writing under lockdown from our homes in New York City and the California Bay Area, we are struck by how the right to science provides a uniquely clarifying framework for thinking through a human rights-based response to this new global pandemic. This moment in late April 2020 is likely to be remembered as the ferocious opening chapter of an epidemic of unknown length. Against this indeterminate time horizon, TB advocacy provides instructive lessons on what it will take to sustain scientific progress against COVID-19 - not over months, but years.

Past experiences from TB and HIV advocacy illuminate possible paths for translating scientific advances against COVID-19 into an effective, evidencebased, and equitable public health response. Presently, the weight of advocacy has settled on the equity proposition of COVID-19 research, or the extent to which scientific advances will be accessible to all who need them. Activists from diverse health movements have jointly called on governments to commit to making the benefits of COVID-19 research available to all without discrimination. ${ }^{85}$ For example, recalling that Jonas Salk refused to patent the world's first polio vaccine or grant exclusive rights to any single company, students and artists have formed "Salk teams" to devise creative ways to pressure universities, governments, and

84 P. Farmer. Pathologies of power: rethinking health and human rights. American Journal of Public Health. 1999; 89(10): 1486-1496.

85 For example, over 500 organizations signed the COVID-19 Principles for Global Access, Innovation and Cooperation urging governments and corporations to share medical advances and "promote access for all." See: Public Citizen [on behalf of over 500 signatories]. COVID-19: principles for global access, innovation, and cooperation. April 23, 2020. www.citizen.org/article/covid-19-principles -for-global-access-innovation-and-cooperation/ 
pharmaceutical companies to make tools against COVID-19 universally available at affordable prices. ${ }^{86}$

Advocacy to promote the development, diffusion, and conservation of science in the TB space has prepared activists to play a watchdog role over the repurposing of existing medical technologies for COVID-19. Activists decried the high price of a SARS-CoV-2 diagnostic cartridge run on a decades-old platform developed for TB through mostly public funding. ${ }^{87}$ Pointing out that the innovation race against COVID-19 has proceeded without robust community engagement, over 200 organizations issued a call for greater participation in COVID-19 R\&D. ${ }^{88}$ Several groups are now partnering to establish a global CAB to advise COVID-19 research endeavors. ${ }^{89}$ Based on their experience with other epidemics, these activists understand the centrality of participation for global health equity.

Right to science principles are latent within many of these initiatives. Yet, most commentaries on human rights and Covid-19 available at the point of writing including statements by UNAIDS, ${ }^{90}$ scientists and academics, ${ }^{91}$ and activists - do not name the right. Thus, COVID-19 also presents an opportunity to raise awareness of the right to science as an analytical and organizing tool. Notably, a UNDP analysis applying lessons learned from the TB and HIV responses to COVID-19 explicitly points to the right to science, particularly its underlying value of transparency "as a critical enabler of both innovation of and access to health technology." ${ }^{2}$

COVID-19 has revealed the imperative of fostering greater international cooperation in science, of which transparency is one essential component. ICESCR Article 15.4 speaks of "international contacts and co-operation," and General Comment No.

In 1955, Jonas Salk, in reply to a question from Edward Murrow about the ownership of the polio vaccine, said: "Well, the people, I would say. There is no patent. Could you patent the sun?" (See: C. DeCroes Jacobs. Jonas Salk: a life. Oxford: Oxford University Press; 2015.) In this spirit, the Salk teams "to free the COVID-19 vaccine" are a joint effort of the Center for Artistic Activism and Universities Allied for Essential Medicines.

${ }_{7}$ Treatment Action Group. Statement on the high price of Cepheid's Xpert test for COVID-19. March 27, 2020. www.treatmentactiongroup.org/statement/treatment-action-group-statement-on-thehigh-price-of-cepheids-xpert-test-for-covid-19/.

88 AVAC [on behalf of over 200 signatories]. Advocates call for ethical research for COVID-19 solutions. April 8, 2020. www.avac.org/blog/advocates-call-ethical-research-covidı.

89 Treatment Action Group and AVAC. Statement on Ethical Conduct of SARS-CoV-2 Vaccine Challenge Studies. May 8, 2020. www.treatmentactiongroup.org/statement/avac-and-tag-statementon-ethical-conduct-of-sars-cov-2-vaccine-challenge-studies/.

90 UNAIDS. Rights in the Time of COVID-19: lessons from HIV for an effective, community-based response. March 20, 2020. www.unaids.org/en/resources/documents/2020/human-rights-andcovid-19.

${ }^{91}$ See, for example, Achieving A Fair and Effective COVID-19 Response: An Open Letter to VicePresident Mike Pence, and Other Federal, State, and Local Leaders from Public Health and Legal Experts in the United States. March 6, 2020. https://law.yale.edu/sites/default/files/area/center/ghjp/ documents/march6_2020_final_covid-19_letter_from_public_health_and_legal_experts_2.pdf.

$9^{2}$ T. Avafia, et al. A rights-based response to COVID-19: lessons learned from HIV and TB epidemics. Health and Human Rights. March 24, 2020. www.hhrjournal.org/2020/03/a-rights-based-response-tocovid-19-lessons-learned-from-hiv-and-tb-epidemics/\#_edn3. 
25 paragraph 82 explicitly references pandemics because, as we are currently witnessing, "a local epidemic can become very quickly a pandemic with devastating consequences." States therefore should respond with transparency by "sharing the best scientific knowledge and its applications ..."93 States and global agencies have put forward several concrete proposals to facilitate greater information sharing and research collaboration (though these stand against rights-denying actions by other states to control information, privatize knowledge, trade collaboration for competition, and undermine global solidarity). To take one positive example, UNESCO held a meeting in March 2020 on international cooperation in the face of COVID-19 to discuss the potential of sharing knowledge - building on its two-year process to develop a Recommendation on Open Science. ${ }^{94} 95$ Another promising example is the proposal by the government of Costa Rica - endorsed by the WHO - to establish a voluntary pool of COVID-19 patents, data, and technology that could be shared for developing drugs, vaccines, and diagnostics. ${ }^{96} \mathrm{We}$ cannot help but hear echoes of the Life Prize concept for TB drug development in this proposal and hope that governments step forward to support it.

With no tests, treatments, or vaccines available at the outset of the pandemic, and with country after country struggling with similar dire situations (e.g., shortages of personal protective equipment, ventilators, testing reagents) within weeks of each other, it is clear that societies must rally around scientific progress as a fundamental human right. The future will depend on states working in collaboration with each other, the private sector, and civil society to ensure that the fruits of scientific innovation - be it medicines, diagnostics, or vaccines developed for COVID-19, $\mathrm{TB}$, or other diseases - are affordable and accessible for all across the globe, just as the right to science demands.

93 See para. 82 of Committee on Economic, Social and Cultural Rights. General comment No. 25 (2020) on Science and economic, social and cultural rights Art. 15.1.b, 15.2, 15.3 and 15.4. E/C.12/GC/ 25 (April 7, 2020). www.ohchr.org/en/hrbodies/cescr/pages/cescrindex.aspx.

94 UNESCO. Open Science. https://en.unesco.org/science-sustainable-future/open-science.

95 UNESCO. UNESCO mobilizes 122 countries to promote open science and reinforced cooperation in the face of COVID-19. March 30, 2020. https://en.unesco.org/news/unesco-mobilizes-122-countries -promote-open-science-and-reinforced-cooperation-face-covid-19.

96 Ed Silverman. WHO director endorses a voluntary intellectual property pool to develop Covid-19 products. STAT. April 6, 2020. www.statnews.com/pharmalot/2020/04/06/covid19-coronaviruspatents-voluntary-pool-world-health/. 